\title{
Índice de avaliação da qualidade de infraestruturas cicloviárias: um estudo em João Pessoa-PB
}

\author{
Quality assessment index of cycling infrastructures: a study in João Pessoa-PB
}

Diogo Gomes Pereira Batista[a] (1), Eduardo Rodrigues Viana de Lima[a] (1)

[a] Universidade Federal da Paraíba (UFPB), João Pessoa, PB, Brasil

Como citar: Batista, D. G. P., \& Lima, E. R. V. (2020). Índice de avaliação da qualidade de infraestruturas cicloviárias: um estudo em João Pessoa-PB. urbe. Revista Brasileira de Gestão Urbana, 12, e20190086. https://doi.org/10.1590/21753369.012.e20190086

\section{Resumo}

Assegurar a qualidade de infraestruturas para o uso de bicicletas é uma das formas de favorecer a acessibilidade cicloviária, contribuindo assim para uma mobilidade urbana mais sustentável. 0 objetivo do artigo é elaborar um Índice de Avaliação da Qualidade de Infraestruturas Cicloviárias e aplicá-lo para analisar as condições de acessibilidade cicloviária das ciclovias e ciclofaixas existentes em João Pessoa-PB. A metodologia corresponde a uma pesquisa bibliográfica sobre métodos de avaliação da qualidade de sistemas cicloviários, como parâmetro para o desenvolvimento do índice proposto, prosseguindo com uma pesquisa de campo e coleta de dados necessários para aplicação. Os resultados contribuem com um mapeamento e diagnóstico da situação atual da cicloestrutura de João Pessoa, além de fornecer novos parâmetros metodológicos de análise através da elaboração e aplicação do índice, composto por quatro categorias e doze indicadores. Revela-se uma série de vulnerabilidades quanto às condições das ciclovias e ciclofaixas, sobretudo quanto à sinalização, demonstrando a necessidade de intervenção de acordo com o desempenho da avaliação e contribuindo assim para ações de planejamento.

Palavras-chave: Mobilidade urbana sustentável. Transporte ativo. Bicicleta. Acessibilidade cicloviária. Indicadores.

\section{Abstract}

Ensuring the quality of cycling infrastructure is one of the ways to promote the cycling accessibility, which contributes to a more sustainable urban mobility. The aim of this paper is to elaborate a Quality Assessment Index of Cycling Infrastructures and apply it for analyzing the cycling accessibility conditions of the existing cycle paths and cycle lanes in João Pessoa. The methodology corresponds to a bibliographic research about methods of quality evaluation of bicycle systems, as a parameter for the development of the proposed index, continuing with a field research and data collection necessary for the application. The results contribute to a mapping and diagnosis of the current situation of João Pessoa's cycle structure. In addition, to providing new methodological parameters of analysis through the elaboration and application of the index, composed by 4 categories and 12 indicators. It reveals a series of vulnerabilities 
regarding the conditions of the cycle paths and cycle lanes, especially regarding the signaling, demonstrating the need for intervention according to the performance of the evaluation, and thus contributing to planning actions.

Keywords: Sustainable urban mobility. Active transport. Bicycle. Cycling accessibility. Indicators.

\section{Introdução}

A mobilidade urbana é um tema central e determinante no processo de planejamento dos deslocamentos necessários à população para que esta tenha acesso aos bens, serviços e relações sociais. No entanto, países emergentes, tal como o Brasil, sofrem atualmente as consequências de um modelo rodoviarista, que favorece o uso do transporte individual motorizado em detrimento de outros modos de locomoção. 0 cenário de "crise de mobilidade" torna-se cada vez mais evidente com o aumento dessa frota motorizada, acarretando índices alarmantes de emissões de gases poluentes, altas taxas de ocupação do espaço e o custo intrínseco de infraestrutura, mortes e lesões ocasionadas no trânsito, além de vários outros problemas que acometem a qualidade de vida das pessoas e do meio ambiente (Silva, 2013). Observa-se que, nas políticas de transportes, ao longo de várias décadas, houve poucas medidas a favor da equidade de acesso à cidade, com consequências que vão muito além da questão do ir e vir das pessoas (Vasconcellos, 2014).

Nesse contexto, faz-se necessária uma mudança de paradigma no comportamento de locomoção das pessoas, que requer uma libertação da dependência do uso de automóveis, de modo a valorizar a intermodalidade dos trajetos cotidianos, sobretudo com relação aos modos de transporte menos impactantes. 0 transporte ativo, ou seja, os modos de locomoção através da energia humana, como andar e pedalar, gera benefícios para toda a sociedade, pois proporciona ambientes mais saudáveis com a redução de emissão de gases poluentes, possui menor demanda e custo de infraestrutura, além de uma série de relações sociais que são criadas e contribuem para uma ocupação dos espaços públicos de modo mais saudável. Assim, a adoção de medidas a favor do transporte ativo é um fator importante para a construção de cidades mais sustentáveis e democráticas (Andrade et al., 2016).

Novas pesquisas de avaliações de medidas redutoras dos impactos da motorização excessiva tornam-se cada vez mais importantes, ao enfatizar a qualidade dos deslocamentos no cotidiano considerando os diferentes aspectos para uma mobilidade urbana mais sustentável (Villada \& Portugal, 2015). Nesse sentido, o transporte por bicicleta é promissor, por ser um veículo com grandes benefícios ambientais, sociais e econômicos, razão pela qual "[...] a Organização das Nações Unidas (ONU) elegeu a bicicleta como o transporte ecologicamente mais sustentável do planeta" (Brasil, 2007, p. 40). Contudo, para que as viagens de bicicleta sejam realizadas de modo efetivo, é necessário, entre outros aspectos, dotar os espaços viários com infraestrutura de qualidade. Desse modo, deve-se buscar garantir o conforto, a segurança e a acessibilidade urbana, como forma de facilitar o acesso aos lugares destinados a concretizar as necessidades e os desejos de todas as pessoas, considerando a realidade de cada território e as particularidades de cada modo de transporte.

O lugar de estudo deste trabalho trata-se da cidade de João Pessoa, capital do estado da Paraíba, região Nordeste do Brasil. João Pessoa possui aspectos semelhantes a outras cidades brasileiras com relação à problemática do transporte, como o espraiamento urbano e o consequente aumento das distâncias e dos custos de deslocamento, as dificuldades no sistema público de transporte e o crescimento das taxas de motorização decorrente de um modelo automobilístico-rodoviário urbano. Somam-se a isso o baixo incentivo ao transporte ativo e a falta de infraestrutura adequada, o que prejudica a acessibilidade de pedestres e ciclistas (Passos et al., 2012).

Nesse contexto, o objeto de estudo deste artigo trata-se das cicloestruturas através de ciclovias e ciclofaixas existentes em João Pessoa, considerando a importância da qualidade desses espaços para garantir uma melhor acessibilidade para os ciclistas, sendo esse um dos aspectos que contribuem para a mobilidade cicloviária. João Pessoa ainda possui poucos estudos locais sobre o tema da mobilidade 
cicloviária e suas condicionantes, além da escassez de dados e canais de observação, o que leva aos seguintes questionamentos: Qual a situação atual do sistema de infraestrutura cicloviária existente em João Pessoa? E que tipo de parâmetros interferem na qualidade dos deslocamentos por bicicleta realizados nas cicloestruturas urbanas? Esta pesquisa tem como objetivo elaborar um Índice de Avaliação da Qualidade de Infraestruturas Cicloviárias e aplicá-lo para analisar as condições de acessibilidade cicloviária das ciclovias e ciclofaixas existentes em João Pessoa.

\section{A acessibilidade cicloviária e a importância das infraestruturas cicloviárias}

Segundo Gutiérrez (2012, p. 67), “[...] a mobilidade é uma prática social de deslocamento no território que une desejos e necessidades de deslocamento (requisitos de mobilidade), e capacidades de satisfazê-los" (tradução nossa). Essas capacidades remetem a condições objetivas de caráter público, como a própria "oferta" de infraestrutura viária, os meios e serviços de transporte, bem como a condições subjetivas de caráter privado, como a concepção da viagem, as condições socioeconômicas e de natureza pessoal. Nesse sentido, Gutiérrez (2012) ressalta ainda que é da interação dessas capacidades, necessidades e desejos que resulta as condições de acesso de grupos sociais à vida cotidiana. A busca por uma mobilidade mais sustentável requer condições que potencializem os modos de deslocamentos menos agressivos ambientalmente e mais proveitosos econômica e socialmente.

Segundo Gehl (2015), a apropriação dos espaços públicos pelas pessoas é um fator imprescindível no planejamento urbano, sendo, assim, uma diretriz almejada para o desenvolvimento de cidades mais vivas, seguras, sustentáveis e saudáveis. Naturalmente, cidades com um bom planejamento cicloviário corroboram com a adesão ao uso da bicicleta como transporte de uso cotidiano e, consequentemente, com a vitalidade urbana defendida por Gehl. Além disso, a bicicleta é um veículo não poluente, que contribui para a preservação dos recursos naturais e da qualidade do ar; apresenta diversos ganhos socioeconômicos, com benefícios à saúde física e mental do ciclista; promove uma maior eficiência do uso do espaço público com infraestrutura de menor ocupação e custo; é passível de intermodalidade com outros modos de transporte; é acessível economicamente, e possui baixo custo de manutenção (Illich, 2005; Blue, 2016).

Nesse contexto, veem-se os amplos aspectos positivos de uso da bicicleta, ressaltando-se também que a mobilidade cicloviária requer um pensamento de análise das características intrínsecas à prática social de viagens através da bicicleta, sob aspectos que interferem tanto nas condições objetivas quanto subjetivas, para que, assim, sejam satisfeitos os exercícios dos direitos de cada cidadão de acesso aos bens e serviços básicos, em função da liberdade e responsabilidade de escolha desse modo de deslocamento. A acessibilidade é um dos fatores que favorecem a capacidade de acesso às atividades urbanas e funções de uso do solo, requerendo, para tanto, um planejamento e uma qualidade de infraestruturas viárias que facilitem e garantam os deslocamentos das pessoas e seus bens em dada localidade. Desse modo, garantir uma boa qualidade de infraestruturas para o uso de bicicletas é uma das formas de favorecer a acessibilidade cicloviária, o que contribui, consequentemente para uma melhor mobilidade cicloviária (Gutiérrez, 2012; Andrade et al., 2016).

Nas cidades brasileiras, apenas a partir do início do século XXI, é que se tem registro de avanços mais significativos na implantação de infraestrutura cicloviária. Os investimentos em infraestrutura cicloviária são recentes e ainda muito deficientes em termos de qualidade e planejamento, apesar de a bicicleta sempre ter sido um veículo de grande popularidade no Brasil, sobretudo a partir de meados dos anos 1950, quando se passou a fabricar bicicletas em território nacional. Por muito tempo, a bicicleta foi vista prioritariamente como uso de lazer e esporte, mas recentemente a sua adesão e valorização como uso de transporte vêm aumentando (Brasil, 2007).

Segundo pesquisas sobre o perfil do ciclista brasileiro (Transporte Ativo, 2018), observa-se que a maioria dessas pessoas utiliza a bicicleta para ir ao trabalho, pedalam cinco dias ou mais por semana, utilizam a bicicleta como transporte há mais de cinco anos e têm como importantes motivações de uso a 
rapidez e a praticidade. Por outro lado, os principais problemas do dia a dia correspondem à falta de segurança no trânsito e de infraestrutura cicloviária, que é inexistente ou insuficiente em quase todas as cidades. A melhoria da qualidade e a implantação de infraestrutura cicloviária são também os motivos que fariam as pessoas pedalarem mais e, conforme apontam diversas pesquisas, tais iniciativas, se concretizadas, são capazes de atrair novos usuários (Andrade et al., 2016).

Um sistema cicloviário consiste em todos os elementos de infraestrutura e de suporte para atender às necessidades dos deslocamentos através da bicicleta em meio urbano. Para que seja eficiente, o sistema cicloviário deve ser integrado aos polos geradores de viagens, em uma rede coesa e bem distribuída na cidade, possibilitando uma mobilidade associada aos demais modos de transporte, com infraestrutura de qualidade e acessível (Cardoso \& Campos, 2016). A cicloestrutura, compreendida como os espaços de infraestrutura viária dedicada ao ciclista, é importante para contribuir com aspectos, como a segurança e o conforto. Para tanto, são criados dispositivos de segregação, sinalização e outros elementos que caracterizam diferentes tipos de cicloestrutura, como a ciclovia e a ciclofaixa.

Segundo definições de Brasil (2007), a ciclovia é o espaço destinado exclusivamente à circulação de bicicletas, separado da pista de rolamento dos outros modos de transportes através de elementos de segregação física e delimitação. A ciclofaixa

[...] é o espaço destinado à circulação de bicicletas, contíguo à pista de rolamento de veículos automotores, sendo dela separada por pintura e/ou dispositivos delimitadores denominados de tachas pelo Código de Trânsito Brasileiro (Brasil, 2007, p. 103).

A implantação da cicloestrutura requer um bom planejamento viário para adequar o tipo de cicloestrutura para cada via e suas particularidades, como o direcionamento de fluxo, as conexões, os cruzamentos e a forma urbana. Ademais, entender os diferentes aspectos que influem na qualidade da cicloestrutura para as viagens praticadas através de bicicleta é um fator essencial para planejar seu uso com eficácia e melhoria da mobilidade em geral (Tischer, 2017).

\section{Metodologia}

Para o desenvolvimento deste trabalho, alguns procedimentos metodológicos foram tomados a fim de cumprir o objetivo proposto. A Figura 1 apresenta um fluxograma com o percurso metodológico efetuado. Inicialmente, realizou-se uma pesquisa bibliográfica sobre métodos de avaliação de qualidade de sistemas cicloviários, com ênfase em parâmetros de análise de infraestruturas cicloviárias e suas condicionantes. Para síntese dos principais aspectos da revisão bibliográfica, foi estabelecido um recorte temporal de 10 anos, buscando uma aproximação com trabalhos desenvolvidos para aplicação no contexto das cidades brasileiras. Desse modo, foi possível estabelecer uma investigação de critérios de avaliação que condicionou a formulação do Índice de Avaliação de Qualidade de Infraestruturas Cicloviárias, o QualICiclo, constituído de categorias temáticas e seus respectivos indicadores. 
OBJETIVO: ELABORAR UM ÍNDICE DE AVALIACÃO DA QUALIDADE DE INFRAESTRUTURAS CICLOVIÁRIAS E APLICÁ-LO PARA ANALISAR AS CONDIÇ̃̃ES DE ACESSIBILIDADE CICLOVIÁRIA DAS CICLOVIAS E CICLOFAIXAS EXISTENTES EM JOÃO PESSOA.

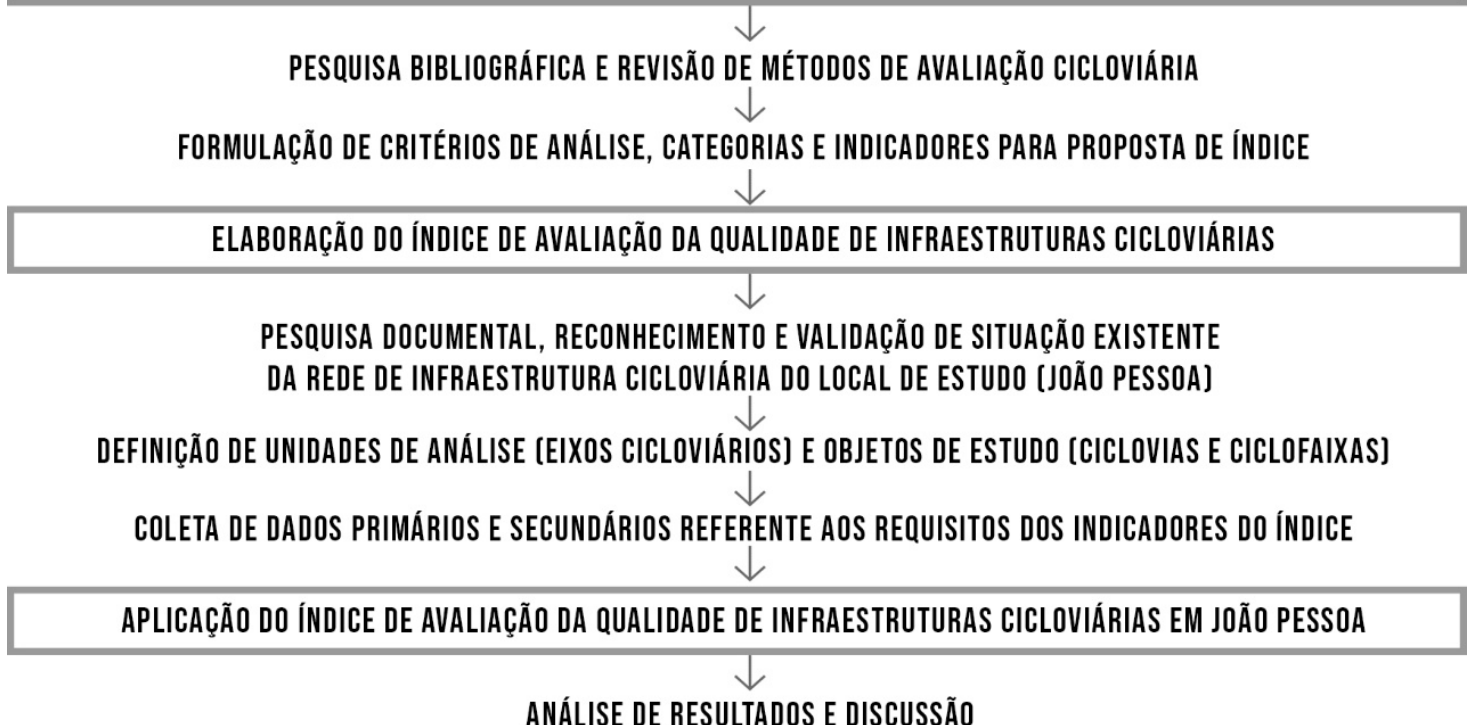

Figura 1 - Infográfico do percurso metodológico. Fonte: Elaboração própria.

Considerando a cidade de João Pessoa como lugar de estudo para aplicação do índice, foi necessário, previamente, realizar uma pesquisa documental e um levantamento de dados para averiguação e reconhecimento da situação existente de infraestrutura cicloviária. Foram realizadas visitas in loco que serviram de base para observações, complementações e validação do registro documental existente, possibilitando também uma aproximação dos autores com o lugar de trabalho. A partir disso, foi determinado como objeto de estudo, o conjunto de cicloestruturas do tipo ciclovias e ciclofaixas da cidade. Em muitos casos, essas cicloestruturas são verificadas de forma fragmentada espacialmente, estendendo-se de um ponto geográfico a outro, como eixos situados em diferentes localidades da cidade. Desse modo, a unidade de análise para estudo foi designada como eixo cicloviário, compreendendo cada trajeto existente e delimitado de cicloestrutura.

Para a seleção de indicadores que iriam compor o índice, alguns critérios foram levados em consideração, como a sua relevância e representatividade, segundo as referências pesquisadas, bem como a disponibilidade de dados e a viabilidade de verificação no local dos principais elementos que compõem a infraestrutura cicloviária. A partir disso, a composição dos distintos indicadores em categorias é proposta como forma de facilitar a compreensão dos mesmos e destacar suas contribuições em temas mais característicos.

Para o sistema de pontuação do índice QualICiclo, foi realizada uma adaptação do método de pontuação do Índice de Caminhabilidade, desenvolvido pelo Instituto de Políticas de Transporte e Desenvolvimento (ITDP, 2018). Desse modo, o sistema de pontuação adotado define - para cada indicador, categoria e índice final - uma escala quantitativa de pontos que varia de 0 (zero) a 3 (três) e, de modo qualitativo, corresponde a uma escala que varia de insuficiente a ótimo, conforme apresentado na Figura 2. Assim, para cada indicador, foram estabelecidos critérios próprios de avaliação, determinados a partir de uma escala de quatro fatores para gerar a pontuação.

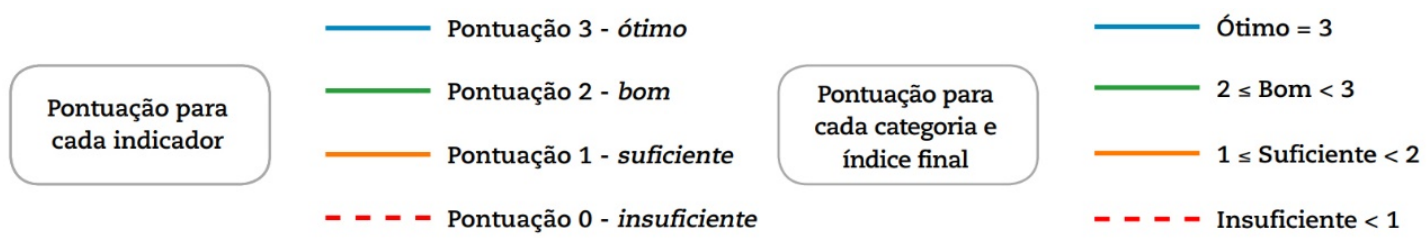

Figura 2 - Sistema de Pontuação adotado para o QuallCiclo. Fonte: ITDP (2018). 
O sistema de pontuação adotado de ITDP (2018, p. 20-21) define as recomendações para cálculo. Em síntese, parte-se de uma nota de 0 a 3 para cada indicador, definindo o valor médio do índice para cada eixo cicloviário, individualmente. Tendo em vista os diferentes comprimentos de cada eixo cicloviário contido em uma cidade, para a aplicação do índice, é necessário calcular a proporção do comprimento que cada eixo representa referente à extensão total dos eixos avaliados. Ou seja, quanto maior o comprimento do eixo cicloviário, maior será seu peso na avaliação final. Assim, são atribuídas as notas percentuais a partir do comprimento de cada eixo cicloviário em relação ao somatório da extensão total do conjunto das ciclovias ou ciclofaixas avaliadas, resultando, assim, em uma pontuação ponderada final para cada indicador, categoria e índice final. Isso será visto e exemplificado nos resultados. Vale ressaltar que não há definição de hierarquia de pesos para diferentes indicadores, categorias ou tipos de cicloestrutura avaliada.

Para a aplicação do índice, foi necessário o levantamento de dados a partir de pesquisa de campo e recursos de georreferenciamento - como a utilização do programa Google Earth para identificação de comprimento de eixos e inclinação -, utilizando-se técnicas como a ficha de registro, as medições in loco, as fotografias, a gravação em áudio e a filmagem de todo o percurso dos eixos avaliados. Desse modo, quantificaram-se os seguintes dados: largura média; tamanho e espaçamento da proteção; irregularidades no pavimento; existência e condições da sinalização horizontal e vertical; iluminação artificial; obstáculos e impedimentos de circulação; velocidade permitida para veículos motorizados e medidas de moderação de tráfego; sombreamento, e contagem de fluxo de ciclistas em horários de pico (6h às $8 \mathrm{~h}$ e $17 \mathrm{~h}$ às $19 \mathrm{~h})$.

A pesquisa de campo foi realizada no período de março a maio de 2018. As informações coletadas foram tratadas e sistematizadas através de softwares para mapeamento espacial (AutoCAD e QGIS) e houve utilização de planilhas eletrônicas (Excel) para cálculos e tabulação de dados. Dessa maneira, obtiveram-se os requisitos necessários para aplicação do índice, subsidiando uma análise e a discussão dos resultados inter-relacionados.

\section{Indicadores de qualidade cicloviária}

Os métodos de avaliação da qualidade de sistemas cicloviários são elaborados por diversos pesquisadores e planejadores com o intuito de gerar informações e contribuir com a melhoria da gestão da mobilidade por bicicleta e a implantação de cicloestrutura frente às dinâmicas urbanas de cada contexto. A partir da revisão bibliográfica realizada neste trabalho, observa-se que as pesquisas sobre as condicionantes de aspectos que influenciam no uso da bicicleta possuem diferentes vertentes e múltiplas variáveis de análise. Como exemplo, algumas das referências mais notáveis foram os trabalhos de Epperson (1994), que elabora o Índice de Condição da Via para avaliar aspectos de segurança para o ciclista; Dixon (1996), que desenvolve um sistema de pontuação de Nível de Serviço para avaliar o uso da bicicleta em corredores viários, e a metodologia proposta no Highway Capacity Manual (TRB, 2000), que traz contribuições para análise da infraestrutura cicloviária através da avaliação da capacidade e do nível de serviço para bicicletas. Esses métodos destacam variáveis de estudo, como as condições de manutenção e largura da via, situações de conflito, volume e velocidade de tráfego.

Estudos mais recentes evidenciam a inserção de outros tipos de variáveis mais abrangentes, ressaltando também aspectos de conforto ambiental, como a inclinação e o sombreamento, e destacando especificidades da infraestrutura cicloviária, como a sinalização (Cardoso \& Campos, 2016). Além disso, a incorporação da percepção de ciclistas gerou contribuições para a descoberta de fatores de influência positiva ou negativa quanto ao uso da bicicleta e aos aspectos socioambientais da mobilidade (Silveira \& Maia, 2015). Conforme apontado, diversos parâmetros podem ser utilizados para diagnóstico dentro do complexo do sistema cicloviário. Para este artigo, deu-se ênfase a métodos de avaliação de qualidade da infraestrutura cicloviária. Desse modo, foram elencadas quatro pesquisas, considerando como critérios de escolha a relevância da metodologia utilizada, a aplicabilidade para o contexto brasileiro e sua atualidade referente aos últimos 10 anos. Esses estudos serviram de base para análise de seus 
indicadores e posterior elaboração de um novo índice para avaliação da qualidade de infraestruturas cicloviárias.

A pesquisa de Providelo \& Sanches (2011) tem o objetivo de desenvolver um modelo de nível de serviço para bicicletas para aplicação em cidades brasileiras de porte médio. A metodologia conduziu à identificação dos atributos mais representativos das características de qualidade de vias para o uso da bicicleta a partir da percepção de um grupo focal de pessoas entrevistadas nas cidades de Rio Claro e São Carlos, ambas do estado de São Paulo. Os resultados dessa pesquisa chamam atenção para alguns indicadores de maior grau de importância sob a ótica das pessoas, como: "largura da via", "velocidade de veículos motorizados", "visibilidade nos cruzamentos", "presença de cruzamentos" e "sombreamento".

A partir de uma revisão literária de métodos de análise de qualidade de infraestrutura cicloviária, de aplicação em diversos países, a pesquisa de Monteiro \& Campos (2011) apresenta um novo método elaborado para analisar os espaços de circulação de bicicletas (ciclovias e ciclofaixas) nas cidades brasileiras. Foram propostos 19 indicadores em cinco categorias que avaliam, sobretudo, questões relacionadas às condições da infraestrutura física e operacional das vias, como a largura da cicloestrutura e o volume de tráfego de ciclistas. Demonstra-se também uma tendência, referente aos métodos estudados por esses autores em estabelecer níveis de serviço de qualificação dos espaços cicloviários.

0 favorecimento do transporte cicloviário não se dá apenas pela quantidade de extensão de cicloestrutura, mas também devido à qualidade dela, referente às várias condicionantes que influem no ato de pedalar. Partindo desse pressuposto, a Associação Metropolitana de Ciclistas do Grande Recife (Ameciclo, 2016) desenvolveu o Índice de Desenvolvimento da Estrutura Cicloviária (IDECiclo), aplicado na cidade de Recife, em Pernambuco. 0 método busca estabelecer avaliações comparativas ao longo do tempo, como forma de subsidiar processos de melhorias no planejamento cicloviário da cidade. Para tanto, são avaliados diferentes tipos de cicloestrutura, como as ciclovias, ciclofaixas e ciclorrotas (via compartilhada sinalizando prioridade ao ciclista), a partir de uma série de indicadores categorizados em aspectos de conforto e segurança. Uma das observações referentes aos resultados de aplicação desse índice é que há uma boa adequação do tipo da cicloestrutura com a velocidade permitida para veículos motorizados; no entanto, destaca-se a falta de medidas de moderação de tráfego para controlar os motoristas infratores.

A Ciclabilidade é um termo derivado de Bikeability, que se refere à pertinência sobre a qual um ambiente favorece o uso da bicicleta, sendo a qualidade da cicloestrutura um fator essencial para esse incentivo. A partir desse conceito, Andrade (2018) desenvolveu uma pesquisa para elaboração de um Índice de Ciclabilidade com foco no uso da bicicleta como meio de transporte, utilizando como local de estudo a cidade de Aracaju, em Sergipe. Algumas fragilidades estudadas nessa pesquisa revelam indicadores peculiares com relação à segurança, como os crimes de trânsito, roubos e furtos. Esse trabalho destaca a importância dos instrumentos de análise de mobilidade para a criação de políticas públicas que deem suporte ao transporte cicloviário.

O Quadro 1 descreve as categorias e os indicadores utilizados por cada uma das quatro referências elencadas a partir da revisão bibliográfica.

Quadro 1 - Síntese da revisão de métodos de avaliação da qualidade de vias para o uso da bicicleta em cidades brasileiras

\begin{tabular}{|c|c|c|}
\hline \multicolumn{3}{|c|}{ MÉTODOS DE AVALIAÇÃO DE QUALIDADE CICLOVIÁRIA NO BRASIL } \\
\hline \multicolumn{3}{|c|}{ CATEGORIAS E INDICADORES } \\
\hline \multicolumn{3}{|c|}{ (Providelo \& Sanches, 2011) (tradução nossa) } \\
\hline $\begin{array}{c}\text { Tráfego: } \\
\text { - Volume de Veículos Motorizados } \\
\text { - Velocidade de Veículos } \\
\text { Motorizados } \\
\text { - Sinalização nos Cruzamentos } \\
\text { - Presença de Veículos Pesados } \\
\text { - Presença de Cruzamentos } \\
\text { - Direcionalidade da Via }\end{array}$ & $\begin{array}{l}\text { Infraestrutura: } \\
\text { - Visibilidade nos Cruzamentos } \\
\text { - Condições do Pavimento } \\
\text { - Largura da Via }\end{array}$ & $\begin{array}{l}\text { Conflitos: } \\
\text { - Entradas e Ruas laterais } \\
\text { - Estacionamento Lateral } \\
\text { - Rotatórias } \\
\text { Meio Ambiente: } \\
\text { - Declividade } \\
\text { - Presença de Arborização } \\
\text { (Sombreamento) }\end{array}$ \\
\hline
\end{tabular}


Quadro 1 - Continuação...

\begin{tabular}{|c|c|c|}
\hline \multicolumn{3}{|c|}{ MÉTODOS DE AVALIAÇÃO DE QUALIDADE CICLOVIÁRIA NO BRASIL } \\
\hline \multicolumn{3}{|c|}{ (Monteiro \& Campos, 2011) } \\
\hline $\begin{array}{c}\text { Facilidade e Conforto: } \\
\text { - Presença de Ciclovia ou } \\
\text { Ciclofaixa } \\
\text { - Largura efetiva da Ciclovia ou } \\
\text { Ciclofaixa } \\
\text { - Regularidade do Pavimento } \\
\text { - Presença de Arborização } \\
\text { - Presença de lluminação } \\
\text { Seguridade: } \\
\text { - Policiamento } \\
\text { - Número de Assaltos }\end{array}$ & $\begin{array}{l}\text { Acessibilidade e Mobilidade: } \\
\text { - Desnível do Terreno } \\
\text { - Rampas de Acesso nos } \\
\text { cruzamentos ou passarelas } \\
\text { - Volume de Ciclistas } \\
\text { - Presença de Bicicletários } \\
\text { Localização: } \\
\text { - Densidade de Ocupação } \\
\text { - Tipo de Uso do Solo }\end{array}$ & $\begin{array}{c}\text { Segurança: } \\
\text { - Travessias Seguras por meio de } \\
\text { sinalização ou passarelas } \\
\text { - Distância Segura do fluxo de } \\
\text { veículos motorizados } \\
\text { - Volume de Veículos na via no } \\
\text { caso de ciclofaixas } \\
\text { - Número de acidentes } \\
\text { - Número de Entradas para } \\
\text { veículos motorizados } \\
\text { - Velocidade do Fluxo de veículos } \\
\text { motorizados }\end{array}$ \\
\hline \multicolumn{3}{|c|}{ (Ameciclo, 2016) } \\
\hline $\begin{array}{c}\text { Segurança: } \\
\text { - Adequação da estrutura } \\
\text { cicloviária ao Código de Trânsito } \\
\text { Brasileiro } \\
\text { - Proteção da Estrutura } \\
\text { - Controle de Velocidade } \\
\text { Máxima da via } \\
\text { - Continuidade da Sinalização } \\
\text { Horizontal nos cruzamentos }\end{array}$ & $\begin{array}{c}\text { - Largura da estrutura cicloviária } \\
\text { - Sinalização Horizontal } \\
\text { - Sinalização Vertical ao longo da } \\
\text { infraestrutura } \\
\text { - Sinalização Vertical nas vias que } \\
\text { cruzam a infraestrutura } \\
\text { - Padrão de Pintura } \\
\text { - Condição da Sinalização } \\
\text { Horizontal } \\
\text { - Situações de Risco }\end{array}$ & $\begin{array}{l}\text { Segurança e Conforto: } \\
\text { - Sinuosidade do traçado } \\
\text { Conforto: } \\
\text { - Bidirecionalidade da estrutura } \\
\text { - Sombreamento } \\
\text { - Tipo de Pavimento } \\
\text { - Situação do Pavimento } \\
\text { - Existência de obstáculos }\end{array}$ \\
\hline \multicolumn{3}{|c|}{ (Andrade, 2018) } \\
\hline $\begin{array}{l}\text { Ciclovia / Ciclofaixa: } \\
\text { - Material do Piso } \\
\text { - Condição da Sinalização } \\
\text { Horizontal e Vertical } \\
\text { - Condição do Piso }\end{array}$ & $\begin{array}{l}\text { Ambiente: } \\
\text { - Arborização } \\
\text { - Poluiçãoo Sonora } \\
\text { - Resíduos Sólidos } \\
\text { Atração: } \\
\text { - Permeabilidade Física } \\
\text { - Fluxo de Ciclistas }\end{array}$ & $\begin{array}{c}\text { Segurança Pública: } \\
\text { - lluminação } \\
\text { - Roubos e Furtos } \\
\text { Segurança Viária: } \\
\text { - Velocidade de veículos } \\
\text { motorizados } \\
\text { - Crimes de Trânsito }\end{array}$ \\
\hline
\end{tabular}

Fonte: Elaboração própria.

De modo geral, as aplicações dos métodos avaliados revelam índices alarmantes quanto à situação de vulnerabilidade da infraestrutura cicloviária, sendo necessária uma ampla política de valorização da mobilidade cicloviária e investimentos para o planejamento e a gestão mais eficientes desse setor. Essas referências refletem uma tentativa de obter métodos com medidas tão íntegras quanto possíveis, de maneira mais ou menos abrangente e funcional. Desse modo, essa revisão serviu de suporte para a elaboração de um novo índice, considerando a necessidade de melhor conciliar as variáveis com maior compatibilidade, buscando medidas mais objetivas e práticas, com categorias e indicadores substanciados a partir dos parâmetros de maior notoriedade.

Entre as principais semelhanças observadas na revisão dos métodos, a categoria Segurança é a mais abordada, tratando de situações de risco para os ciclistas, seja através de elementos da infraestrutura (em maior amplitude) e do trânsito, seja através de elementos de segurança pública. Ressalta-se a dificuldade de obter dados quantitativos referentes a aspectos de seguridade, como policiamento, acidentes e crimes. No entanto, outros elementos afetam esse tipo de segurança de forma indireta, como a iluminação e o fluxo de ciclistas. Assim, a categoria Segurança naturalmente adequa-se como integrante analítico.

Outro indício de categoria é a que trata de particularidades da cicloestrutura, em que há uma série de indicadores possíveis, com semelhanças e especificidades, destacando-se a sinalização como um componente de influência importante para a segurança e a legitimidade do sistema cicloviário. Haja vista a relevância de elementos próprios da Cicloestrutura e a singularidade e a relevância da Sinalização, como igualmente destacado por Cardoso \& Campos (2016), esses temas foram considerados como categorias fundamentais. A presença de bicicletário é sugerida apenas por Monteiro \& Campos (2011), apesar da sua função essencial. Considera-se assim essa variável como um componente à parte, mais propícia para 
uma avaliação da mobilidade em maior escala e não particularmente sobre as condições para circulação cicloviária.

Entre os indicadores mais evidentes e que corroboram como segmentos das categorias temáticas, destacam-se Sinalização, Pavimentação, Velocidade dos Veículos Motorizados na via, Largura e Sombreamento. Apesar do destaque de alguns indicadores, outros em menor evidência são importantes, como a iluminação e a declividade, pois conduzem a aspectos de conforto ambiental, uma questão considerada significativa nos estudos sobre o uso da bicicleta, especialmente tratando-se do contexto brasileiro. Dentre os sistemas de mensuração e pontuação observados, o método do ITDP (2018) adaptado por Andrade (2018) mostrou-se eficaz, compreensível e mais apropriado para ser utilizado em uma nova proposição. Conforme demonstrado, há uma tendência em estabelecer métodos de avaliação a partir de diferentes indicadores que contribuem para um diagnóstico mais preciso e objetivo, dando suporte para um planejamento mais estratégico da mobilidade cicloviária. A proposta do novo índice para avaliar a qualidade de infraestruturas cicloviárias é apresentada a seguir, de modo a sintetizar os parâmetros de maior destaque e considerados de maior influência em aspectos gerais.

\section{Índice de avaliação da qualidade de infraestruturas cicloviárias (QuallCiclo)}

O índice de Avaliação da Qualidade de Infraestruturas Cicloviárias (QualICiclo) é constituído por 12 indicadores sobre diferentes aspectos que influenciam na qualidade da prática de pedalar em ciclovias e ciclofaixas. Os indicadores foram divididos em quatro categorias que representam uma dimensão mais global de cada grupo de três indicadores. As categorias mantêm relações diretas entre si e referem-se a Cicloestrutura, Sinalização, Ambiente e Segurança. O Quadro 2 apresenta o índice com a distribuição de suas categorias e indicadores, mais detalhados em seguida. Observa-se que o QuallCiclo possui indicadores semelhantes àqueles encontrados na revisão bibliográfica, mas com uma nova estruturação de parâmetros e categorias temáticas. Destarte, buscou-se um modelo mais perceptível de itens considerados mais relevantes quanto às especificidades e necessidades locais. 0 número de indicadores em comparação àqueles apresentados anteriormente foi reduzido de modo a simplificar e tornar mais prático o uso do método.

Quadro 2 - Índice de Avaliação da Qualidade de Infraestruturas Cicloviárias, indicando as quatro categorias e os 12 indicadores

\begin{tabular}{|c|c|c|}
\hline ÍNDICE & CATEGORIAS & INDICADORES \\
\hline \multirow{12}{*}{$\begin{array}{c}\text { Avaliação da Qualidade de } \\
\text { Infraestruturas Cicloviárias } \\
\text { (QuallCiclo) }\end{array}$} & \multirow{3}{*}{ Cicloestrutura } & Largura \\
\hline & & Proteção \\
\hline & & Pavimento \\
\hline & \multirow{3}{*}{ Sinalização } & Horizontal \\
\hline & & Vertical \\
\hline & & Qualidade \\
\hline & \multirow{3}{*}{ Ambiente } & Inclinação \\
\hline & & Sombreamento \\
\hline & & lluminação \\
\hline & \multirow{3}{*}{ Segurança } & Situações de Risco \\
\hline & & Moderação de Tráfego \\
\hline & & Densidade \\
\hline
\end{tabular}

Fonte: Elaboração própria.

\section{Categoria: cicloestrutura}

A categoria Cicloestrutura se refere à infraestrutura cicloviária, tratando-se neste trabalho especificamente das ciclovias e ciclofaixas, no tocante a suas características físicas mais básicas, necessárias para um deslocamento com comodidade, prevenção de conflitos e fluidez. Os indicadores 
relativos à Cicloestrutura são: Largura, Proteção e Pavimentação. A largura refere-se ao espaço útil da cicloestrutura para circulação adequada para pessoas de bicicleta. A largura pode diferir conforme a direcionalidade da via ciclável, podendo ser unidirecional, com sentido único, ou bidirecional, com sentido duplo de fluxo de ciclistas. A proteção da cicloestrutura está relacionada aos elementos de segregação física completa para ciclovias ou de proteção parcial, através de tachões, para ciclofaixas, com o intuito de impedir a invasão do tráfego motorizado e delimitar o uso exclusivo de ciclistas (Brasil, 2007). A pavimentação, por sua vez, refere-se ao estado material do pavimento, considerando seus aspectos de superfície e conservação, de forma a não conter irregularidades e deteriorações que possam comprometer o tráfego de ciclistas.

\section{Categoria: sinalização}

A categoria Sinalização corresponde aos elementos e dispositivos de comunicação viária necessários para um trânsito eficiente de ciclistas e em conformidade com os demais modos de transporte e características da via. Para tanto, a categoria é composta dos indicadores de sinalização Horizontal, Vertical e Qualidade da sinalização. A sinalização horizontal corresponde aos componentes de orientação viária de piso, geralmente com indicações através de pintura. Já a sinalização vertical trata-se dos dispositivos de regulamentação viária através de placas e semáforos dedicados ao ciclista. Para esses indicadores, foram observados aspectos mais voltados a sua presença ao longo de cada eixo cicloviário, delimitação da cicloestrutura, regulação de sentido de fluxo, advertências, indicações de rotas e marcação de travessias seguras nos cruzamentos. A qualidade da sinalização caracteriza-se como um indicador particular das condições de manutenção, conservação, visibilidade e aparência, tanto da sinalização horizontal quanto vertical (ITDP, 2017).

\section{Categoria: ambiente}

A categoria Ambiente trata de características do meio ambiente urbano que influenciam no bem-estar do tráfego cicloviário a partir das condições da forma urbana e dos confortos térmico e lumínico. Para tanto, foram definidos os indicadores de Inclinação, Sombreamento e Iluminação. A inclinação topográfica das vias corresponde a um fator que impacta diretamente no grau de esforço físico necessário para pedalar, além de situações desfavoráveis, quando há um grau acentuado de aclives e declives. A interferência da inclinação está relacionada com o comprimento máximo da extensão viária e o seu percentual de inclinação, ou seja, quanto mais inclinada a via, menor deve ser essa extensão, para que não comprometa o ato de pedalar (AASHTO, 1999). A arborização ou até mesmo a presença de elementos edificados que gerem sombra favorece significativamente o conforto térmico do ciclista, sobretudo em países como o Brasil, que possui regiões de clima quente e alta insolação. Além disso, a arborização traz diversos benefícios ambientais para todo o ecossistema urbano, como a influência no controle do ruído e da radiação solar, na melhoria da qualidade do ar e na percepção de bem-estar (Maruyama \& Simões, 2014). A iluminação, avaliada neste trabalho, por sua vez, refere-se à iluminação pública artificial dos períodos noturnos. Vias com iluminação adequada para as pessoas de bicicleta são importantes para a visibilidade e o conforto lumínico, além de proporcionar uma maior percepção de segurança pública.

\section{Categoria: segurança}

A categoria Segurança incorpora diferentes aspectos que interferem na segurança viária, como forma de identificar situações conflitantes que geram um ambiente hostil para pedalar. Assim, foram determinados os indicadores de Situações de Risco, Moderação de Tráfego e Densidade. As situações de risco podem ser observadas de diversas formas, como a presença de obstáculos, o traçado irregular da 
cicloestrutura e a sua má implantação ou interrupção inadequada, entre outros tipos de impedimentos e situações conflituosas de circulação que requerem muita atenção do ciclista.

As medidas de moderação de tráfego ou traffic calming são caracterizadas como concepções e incorporação de soluções de desenho urbano e planejamento viário para promover a segurança no trânsito. Como exemplos de medidas de moderação de tráfego, temos os elementos físicos de redução de velocidade, como lombadas e sonorizadores, além da própria sinalização viária. A compatibilidade da velocidade de veículos motorizados na via é um fator importante relativo à adequação quanto ao tipo de cicloestrutura a ser implantado, sendo necessária uma maior segregação da cicloestrutura de acordo com a velocidade máxima permitida. Para este trabalho, foram adotadas as recomendações que preveem a necessidade de ciclovias para vias como velocidade acima de $40 \mathrm{~km} / \mathrm{h}$ e de ciclofaixas para velocidade acima de $30 \mathrm{~km} / \mathrm{h}$ até $40 \mathrm{~km} / \mathrm{h}$ (Brasil, 2007).

Diversos estudos demonstram que quanto mais pessoas pedalando nas ruas, maior será a segurança para todos. Assim, desenvolvem-se melhorias para o comportamento de trânsito, a legitimidade do ato de pedalar, a percepção de segurança pública, a valorização e a atratividade desse modo de deslocamento, em um ciclo virtuoso de maior respeito e segurança (Blue, 2016). 0 indicador densidade corresponde ao número de pessoas de bicicleta por minuto, identificadas a partir de contagens de fluxo nas quais se avaliou a proporção da densidade média de ciclistas.

\section{Aplicação do QuallCiclo em João Pessoa}

A cidade de João Pessoa foi definida como lugar de estudo para este trabalho (Figura 3). Segundo estimativas de IBGE (2018), o município possui uma população de aproximadamente 800.000 habitantes, com território de $211,475 \mathrm{~km}^{2}$ em área litorânea, clima tropical quente e úmido, e vegetação predominante do bioma Mata Atlântica. Com relação ao sistema cicloviário, os resultados da pesquisa documental, do reconhecimento e do mapeamento da situação existente demonstram que a cidade possui cerca de $20 \mathrm{~km}$ de extensão de ciclovias em seis eixos segmentados e $23 \mathrm{~km}$ de ciclofaixas em 12 eixos. Além disso, a cidade possui dois eixos de ciclorrotas com cerca de $3 \mathrm{~km}$ e cicloestruturas de lazer e esporte, situadas em parques ou de uso temporário com aproximadamente $14 \mathrm{~km}$. A Figura 4 apresenta a localização dos eixos cicloviários de acordo com a classificação proposta dos tipos de cicloestruturas existentes em João Pessoa. A maior parte da cicloestrutura da cidade foi implantada apenas a partir de 2010. Nesse contexto, a aplicação do QualICiclo foi realizada tomando como objeto de estudo a totalidade de 18 eixos cicloviários, referentes às cicloestruturas do Tipo A (ciclovia) com seis eixos e do Tipo $\mathrm{B}$ (ciclofaixa) com 12 eixos.

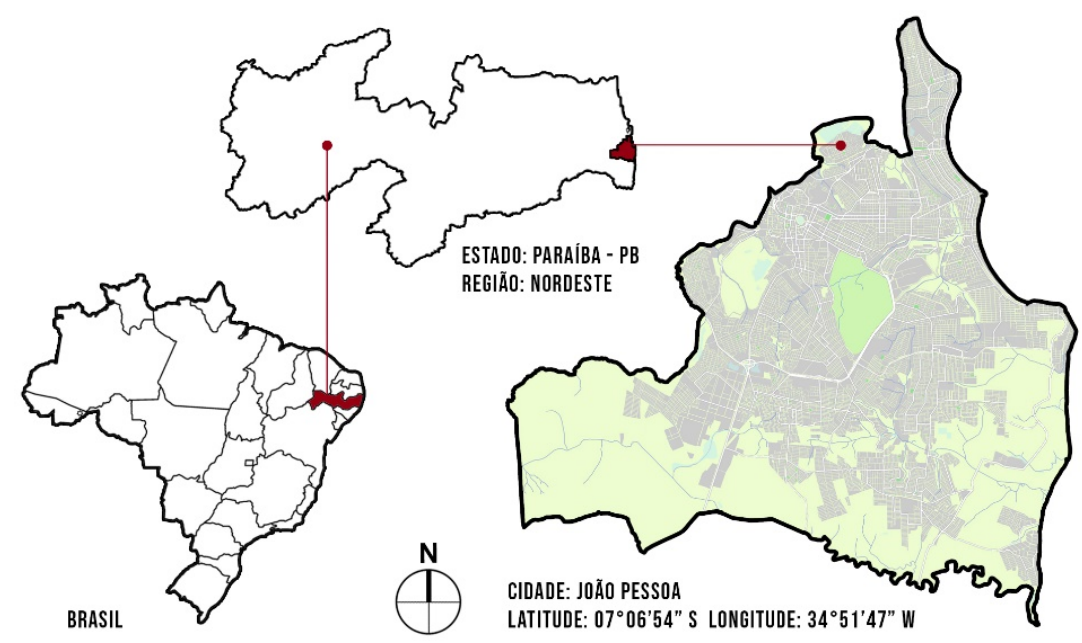

Figura 3 - Mapa de localização de João Pessoa-PB. Fonte: Elaboração própria. 


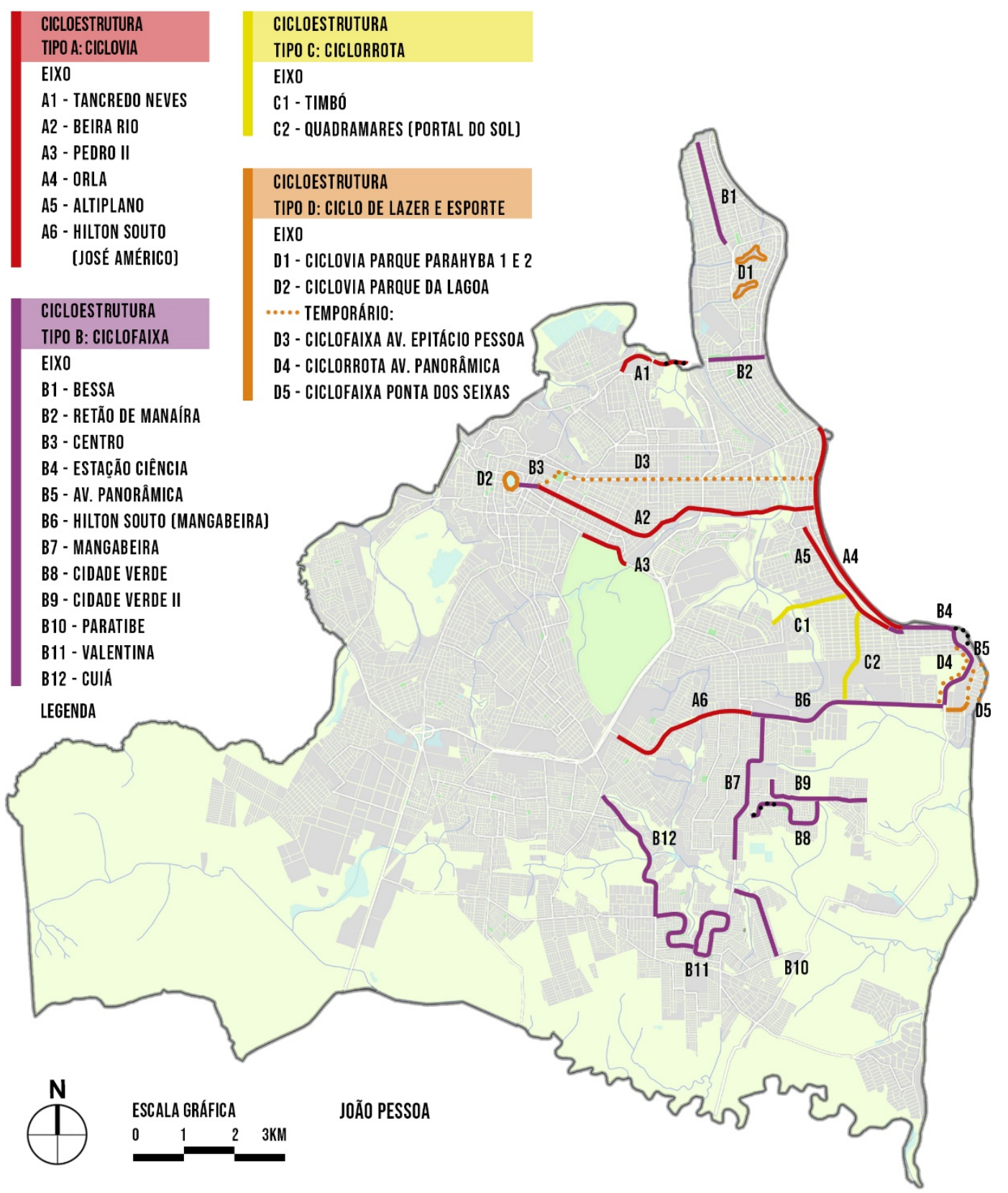

Figura 4 - Mapa de localização e classificação da infraestrutura cicloviária existente em João Pessoa. Fonte: Elaboração própria.

A aplicação do QualICiclo consistiu, inicialmente, na atribuição da pontuação inicial com base na escala de notas de 0 a 3, qualificadas como: insuficiente (0), suficiente (1), bom (2) e ótimo (3), referente aos 12 indicadores para todos os 18 eixos cicloviários avaliados. Com essa pontuação inicial, temos o valor resultante da média aritmética simples, para cada categoria, e para o índice final de cada eixo cicloviário, em particular. Conforme a existência de vários eixos cicloviários identificados em João Pessoa, foi necessário efetuar a proporção ponderada do comprimento de cada eixo em relação ao comprimento total de ciclovias ou de ciclofaixas. Por exemplo, a ciclofaixa Bessa (eixo B1) possui 1,88km de comprimento, o que corresponde a 8,20\% do total de comprimento das ciclofaixas avaliadas; em seguida, esse valor é multiplicado pela nota inicial de 0 a 3 correspondente a todos os indicadores dessa ciclofaixa. Seguindo esse exemplo para todas as cicloestruturas, obtém-se, através da média aritmética, os valores das notas finais ponderadas para cada indicador, categoria e índice final. Ou seja, o índice permite uma 
avaliação dos eixos de modo individual e conjuntamente. A Figura 5 apresenta os valores de comprimento e o fator de ponderação de cada eixo avaliado. As avaliações foram realizadas separadamente, de acordo com o tipo da cicloestrutura (ciclovia ou ciclofaixa), considerando as suas particularidades. Desse modo, a Figura 6 apresenta os resultados de todas as etapas de aplicação do índice, mostrando o índice individual de cada eixo e as pontuações finais para cada indicador, categoria e tipo de cicloestrutura.

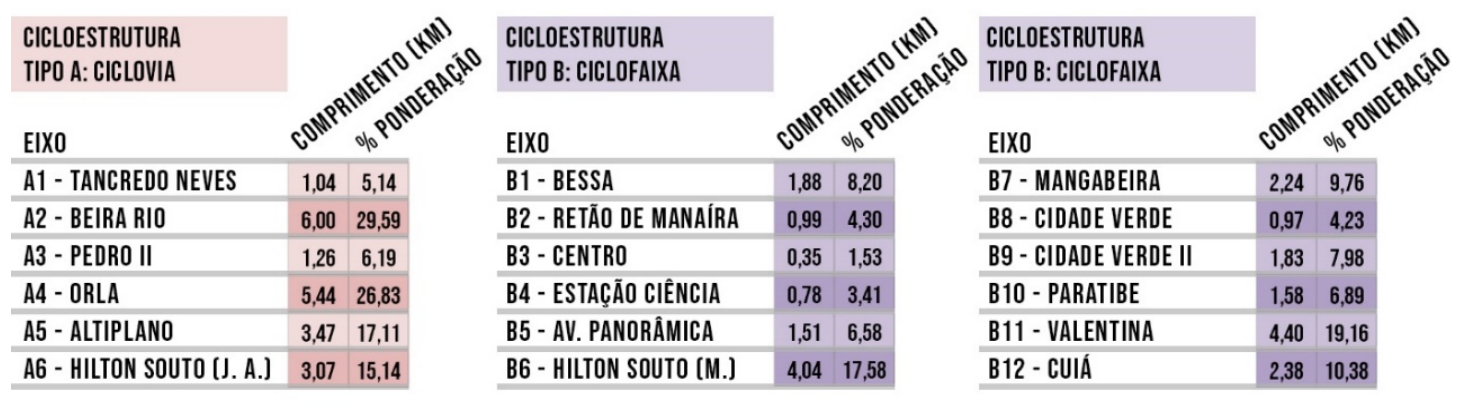

COMPRIMENTO TOTAL:

CICLOVIAS $=20,278 \mathrm{KM}$

CICLOFAIXAS $=22,949 \mathrm{KM}$

Figura 5 - Comprimento dos eixos de ciclovia e ciclofaixa, com valor percentual de ponderação.

Fonte: Elaboração própria.

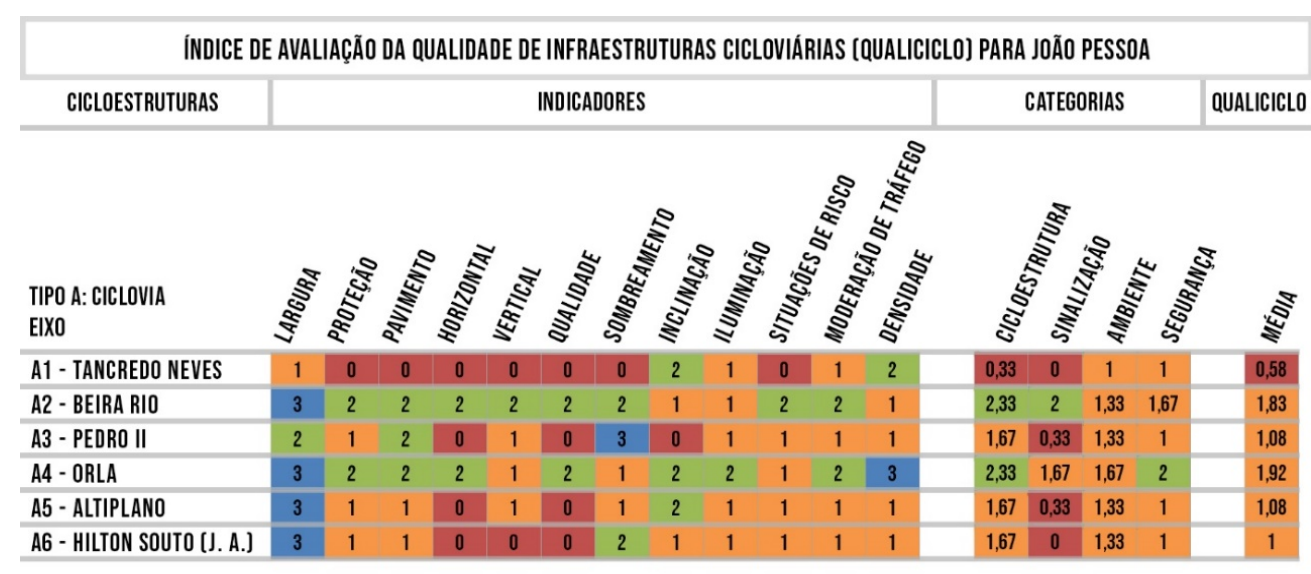

\begin{tabular}{|c|c|c|c|c|c|c|c|c|c|c|c|c|c|c|c|c|c|}
\hline ÍNDICE PARA CICLOVIAS & 2,84 & 1,51 & 1,57 & 1,13 & 1,09 & 1,13 & 1,52 & 1,43 & 1,27 & 1,24 & 1,56 & 1,59 & 1,97 & 1,12 & 1,41 & 1,47 & 1,49 \\
\hline
\end{tabular}

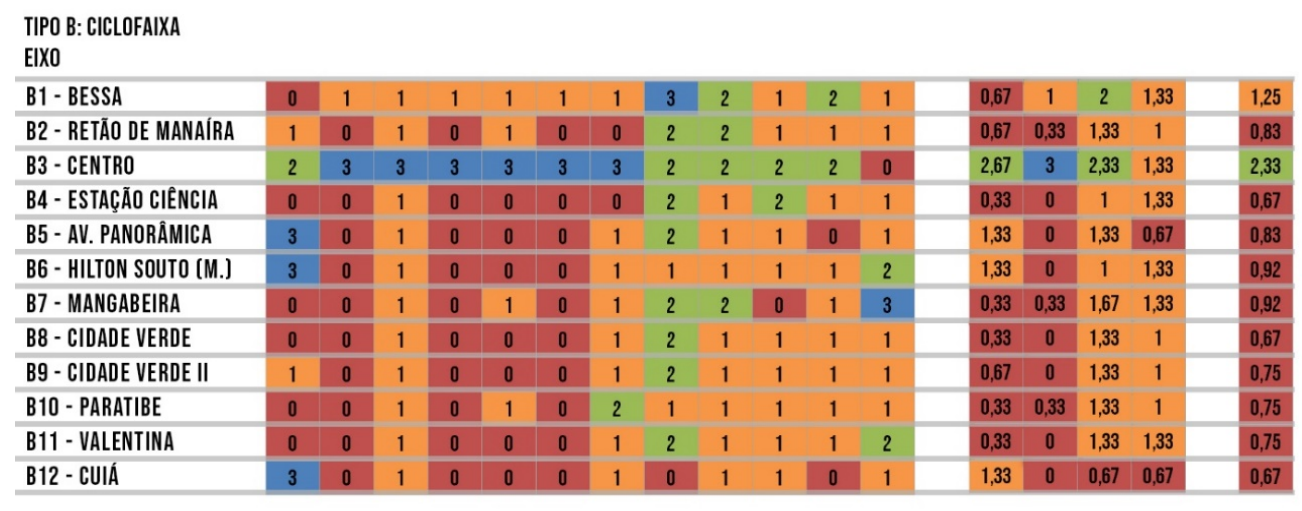

\begin{tabular}{|c|c|c|c|c|c|c|c|c|c|c|c|c|c|c|c|c|c|}
\hline ÍNDICE PARA CICLOFAIXAS & 1,19 & 0,13 & 1,03 & 0,13 & 0,34 & 0,13 & 1,02 & 1,63 & 1,24 & 0,95 & 0,93 & 1,55 & 0,78 & 0,20 & 1,30 & 1,14 & 0,85 \\
\hline
\end{tabular}

Figura 6 - Pontuação dos indicadores, categorias e índice final do QuallCiclo para cada eixo cicloviário. Fonte: Elaboração própria. 
Os resultados do QualICiclo para cada eixo cicloviário, após a pontuação inicial, mostram que a maioria das ciclovias obteve índices com valores de nível suficiente, enquanto a maioria das ciclofaixas, índices de nível insuficiente. No entanto, destaca-se que o menor índice corresponde à ciclovia Tancredo Neves, com nota 0,58, e o maior índice foi para a ciclofaixa Centro, com nota 2,33. Com base nos índices dos eixos cicloviários, verifica-se que algumas cicloestruturas encontram-se na iminência de rebaixar o nível de qualidade de suficiente para insuficiente, tais como as ciclovias Pedro II, Altiplano e Hilton Souto (José Américo). Por outro lado, ciclovias, como a Beira Rio e Orla, estão muito próximas do nível bom. Esse cenário conduz à necessidade de melhorias para potencializar a qualidade desses espaços, principalmente em fatores como a sinalização.

Um dos aspectos observados, com relação à diferença dos índices, deve-se ao fato de que quanto mais antiga a infraestrutura, menor a sua qualidade, sobretudo com relação às categorias de Cicloestrutura e Sinalização. Como exemplo, verifica-se uma situação de abandono, deterioração e falta de manutenção na ciclovia Tancredo Neves, que se encontra em estado de descaracterização em grande parte de sua extensão. Essa cicloestrutura foi implantada na década de 1980, sendo a primeira e única até o início dos anos 2000. Já a ciclofaixa Centro, uma das mais recentes, implantada em 2017, encontra-se em bom estado físico de conservação, visto que possui pouco tempo de uso. Essa situação revela o descaso existente, com relação à administração pública, que não mantém uma gestão eficiente de manutenção da qualidade cicloviária, reduzindo a sua vida útil e gerando insegurança e desvalorização.

Cada eixo cicloviário possui particularidades de acordo com a sua localização, mediante a forma, o uso e as condições ambientais e de infraestrutura urbana. Assim, percebe-se que a avaliação possui algumas pontuações mais distintas, tanto positiva quanto negativamente. Observa-se, por exemplo, com relação às ciclovias, que a Tancredo Neves possui diversos indicadores com péssima qualidade, mas possui uma boa densidade de ciclistas na área, uma vez que a via é importante rota de ligação entre bairros das zonas Norte e Nordeste da cidade. A Pedro II possui uma rota bastante sombreada, devido à sua proximidade com a Mata do Buraquinho, em toda a sua extensão. Com relação às ciclofaixas, ao contrário da Tancredo Neves, a ciclofaixa Centro, que possui a maior média entre todos os eixos, apresenta uma baixa densidade de ciclistas. Uma das averiguações quanto a isso deve-se ao fato de a via estar situada em uma área de baixa densidade populacional e um local muito favorável ao uso do ônibus como transporte. As ciclofaixas da zona sul, como Mangabeira, Hilton Souto e Valentina, possuem níveis de densidade muito positivos, apesar de possuírem diversos indicadores com má avaliação.

$\mathrm{Na}$ análise das notas ponderadas para os indicadores, as categorias e o índice final, verifica-se que, entre as ciclovias, a Largura é o indicador mais positivo, e a Sinalização Vertical, o mais negativo. Já entre as ciclofaixas, a Inclinação foi o mais positivo, com destaque para a ciclofaixa Bessa, que está situada na área mais plana de todos os eixos; já Proteção, Sinalização Horizontal e Qualidade da Sinalização ficaram com os valores mais negativos, em muitos casos com deficiência completa de sinalização, por exemplo. Com relação às categorias, observa-se que a Cicloestrutura das ciclovias possui um nível suficiente, o mais alto, muito próximo do nível bom; já nas ciclofaixas, diferentemente, a categoria com maior pontuação foi Ambiente. A categoria Sinalização foi a de menor nível de avaliação tanto entre as ciclovias quanto entre as ciclofaixas. E, finalmente, foi verificada uma nota suficiente $(1,49)$ em maior medida de qualidade geral para as ciclovias, enquanto as ciclofaixas apresentaram-se com menor avaliação em média, de nível insuficiente $(0,85)$.

Os resultados apresentados oferecem a possibilidade de utilizar os dados como uma hierarquia referente aos eixos cicloviários que mais necessitam de intervenção de melhoria. Assim, cada nível do índice corresponde a recomendações de prioridade de ações, segundo a escala adotada de ITDP (2018), em que: (3) sugere manutenção e aperfeiçoamento; (2 até 2,9) sugere intervenção desejável, ação em médio prazo; (1 até 1,9) sugere intervenção prioritária, ação em curto prazo, e $(0$ até 0,9$)$ sugere intervenção prioritária, ação imediata. 0 mapa da Figura 7 apresenta as cicloestruturas avaliadas com a classificação do índice QualiCiclo de acordo com as notas de pior para melhor qualidade. Observa-se que a maioria das cicloestruturas com más avaliações está situada na zona sul da cidade e são ciclofaixas; além disso, vê-se que a cidade possui eixos desconectados e inexistentes em muitas áreas da cidade. 
LEGENDA:

PONTUAÇ̃̃O / EIXO

ESCALA DE AVALLAC̣̃̃o

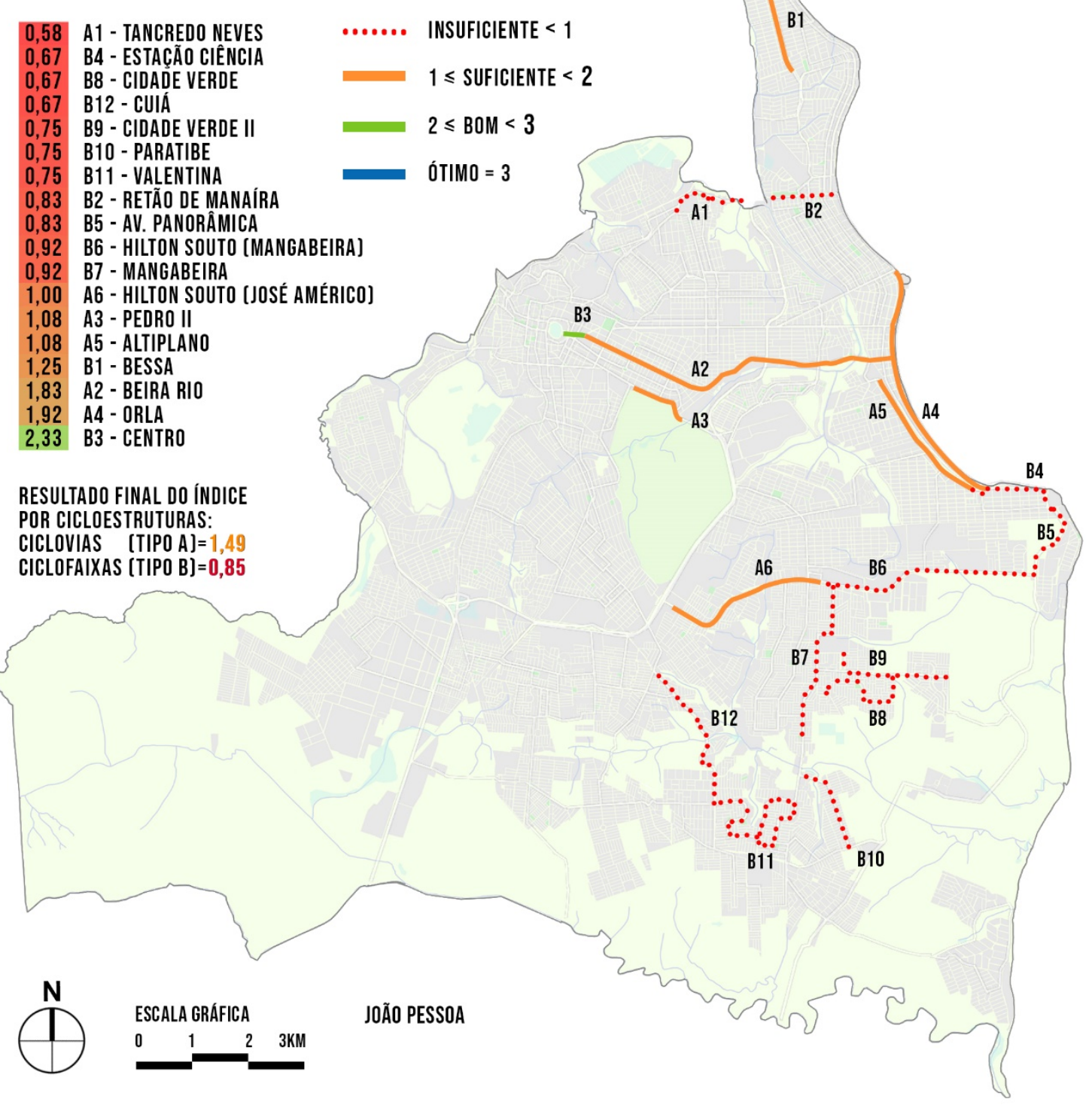

Figura 7 - Mapa da infraestrutura cicloviária de João Pessoa com classificação do Índice QuallCiclo. Fonte: Elaboração própria.

A cicloestrutura mais bem avaliada, a ciclofaixa Centro, é também o eixo de menor extensão, sendo apenas um pequeno trecho de ligação entre a ciclovia Beira Rio e o Parque Sólon de Lucena, no bairro Centro. Já a ciclovia Orla, a segunda melhor avaliada, está localizada em bairros de classe alta e contempla, em grande parte, um dos setores mais turísticos da cidade, sendo uma das poucas cicloestruturas que recebem periódicos investimentos de melhorias. Muitos outros eixos cicloviários possuem necessidades de intervenções mais urgentes, como as ciclofaixas da zona sul, que se encontram em estado precário, mas, mesmo assim, mantém-se uma grande presença de ciclistas. 0 território da zona sul possui um caráter de uso de solo diverso, alta densidade populacional, ambiente e escala favoráveis ao uso da bicicleta, uma área com grande quantidade de viagens em potencial, as quais, no entanto, são realizadas em condições desfavoráveis de infraestrutura. A cidade ainda está longe de possuir um sistema cicloviário eficiente e percebe-se uma desigualdade no modo como os investimentos viários são realizados, priorizando o transporte motorizado ou privilegiando áreas de maior poder aquisitivo e turísticas, além da falta de cicloestrutura que poderia dar maior suporte, gerar mais segurança e incentivar a adesão de transportes ativos, como a bicicleta. 


\section{Conclusões}

A mobilidade varia, entre outros aspectos, conforme a qualidade das condições materiais de caráter público, como a "oferta" de infraestrutura viária de qualidade, assunto abordado através da acessibilidade cicloviária, e a importância das infraestruturas cicloviárias para tal. Assim, esta pesquisa cumpre o seu objetivo de avaliar a qualidade de ciclovias e ciclofaixas de João Pessoa através da elaboração e aplicação de um índice, contribuindo, dessa forma, com parâmetros e dados para auxílio de ações de planejamento, políticas públicas e gestão do modal cicloviário em meio urbano.

A revisão teórica contribuiu com a indicação de diversas variáveis e circunstâncias de análise possíveis sobre a qualidade de um sistema cicloviário, conduzindo a proposta do índice QualICiclo. Esse índice colabora agregando e complementando as variáveis mais notórias, buscando uma melhor composição de fatores e medidas mais compreensíveis, e com potencial de aplicação. Nota-se uma maior similaridade da proposta com abordagens adotadas nos métodos aplicados regionalmente, como os indicadores para Recife (Ameciclo, 2016) e os procedimentos de análise para Aracaju (Andrade, 2018), ambos também não adotaram pesos para os indicadores. Assim, reflete-se a importância de fornecer novos parâmetros metodológicos de análise que se relacionem com aspectos locais, sendo pertinente como recomendação, para trabalhos futuros, a análise comparativa do desempenho desses índices, bem como de outros com parâmetros internacionais para análise, com os quais já se tem uma conformação consagrada de avaliações de mobilidade cicloviária ao longo do tempo.

A completude dos resultados apresentados contribui com um mapeamento e diagnóstico da situação atual da cicloestrutura de João Pessoa. Desse modo, revela-se que esse município apresenta uma série de vulnerabilidades quanto às condições de suas infraestruturas cicloviárias, sobretudo quanto à sinalização, aspecto evidenciado na revisão bibliográfica como um fator importante nos cruzamentos viários e de influência direta na segurança e orientação dos viajantes. Os indicadores propostos refletem a importância de serem observados múltiplos fatores que conferem qualidade ao uso da bicicleta como veículo de transporte. Além disso, foi possível caracterizar não apenas a situação de cada indicador, como também refletir sobre diferentes categorias, evidenciadas em Cicloestrutura, Sinalização, Ambiente e Segurança, que agem de modo inter-relacionado. Demonstra-se também a necessidade de intervenção de melhorias, apresentadas de modo hierárquico com relação ao desempenho de cada um dos 18 eixos cicloviários avaliados.

Algumas dificuldades foram encontradas quanto aos procedimentos realizados neste trabalho, como a carência de dados sobre o sistema cicloviário na cidade, necessitando da realização de grande coleta de dados primários. Como sugestões para trabalhos futuros, é possível a reaplicação do índice em João Pessoa ou em outras cidades, como forma de desenvolver um processo de monitoramento e mensuração das condições da infraestrutura cicloviária de forma periódica, subsidiando um gerenciamento mais eficaz para a tomada de decisões relacionadas à mobilidade urbana.

Diferentes abordagens analíticas, seja de aspectos objetivos ou subjetivos, podem ser integradas de forma sistêmica, permitindo uma análise mais profunda e efetiva das condições de mobilidade em geral, ao longo do contexto sócio-histórico de cada território. Assim, recomenda-se também a observância quanto a outros aspectos que podem ser incorporados de modo complementar ao índice, como medidas de dispersão das notas, a adoção de novos indicadores (como as taxas de acidentes, furtos, densidade e diversidade urbana, bicicletários...), a realização de pesquisas de percepção dos usuários (contribuindo para a definição de pesos para o índice) e outras características do complexo do sistema cicloviário e sua relação com outros modos de transporte.

Nesse contexto, busca-se valorizar novas investigações a respeito do transporte ativo, notadamente através do uso da bicicleta, colaborando com um maior aprofundamento e uma embasada reflexão sobre a mobilidade cicloviária e a sua importância para uma mobilidade mais sustentável. 


\section{Referências}

American Association of State Highway and Transportation Officials - AASHTO. (1999). Guide for the development of bicycle facilities (1a ed.). Washington: AASHTO. Recuperado em 6 de agosto de 2018, de http://www.industrializedcyclist.com/aashto.pdf

Andrade, J. W. C. D. (2018). Desenvolvimento de um índice para a avaliação da ciclabilidade na cidade de Aracaju (Dissertação de mestrado). Universidade Federal de Sergipe, São Cristóvão.

Andrade, V., Rodrigues, J., Marino, F., \& Lobo, Z. (2016). Mobilidade por bicicleta no Brasil (1a ed.). Rio de Janeiro: PROURB/UFRJ.

Associação Metropolitana de Ciclistas do Grande Recife - Ameciclo. (2016). IDECiclo índice de desenvolvimento da estrutura cicloviária. Recife. Recuperado em 4 de novembro de 2017, de http://bit.ly/relatorioideciclo2016

Blue, E. (2016). Bikenomics: como a bicicleta pode salvar a economia (1a ed.). Rio de Janeiro: Babilonia Cultura Editorial.

Brasil. Ministério das Cidades. (2007). Caderno de referência para elaboração de Plano de Mobilidade por Bicicleta nas Cidades. Brasília: Secretaria Nacional de Transporte e da Mobilidade Urbana.

Cardoso, P. B., \& Campos, V. B. G. (2016). Metodologia para planejamento de um de sistema cicloviário. Transportes, 24(4), 39-48. http://dx.doi.org/10.14295/transportes.v24i4.1158.

Dixon, L. B. (1996). Bicycle and pedestrian level-of-service performance measures and standards for congestion management systems. Transportation Research Record: Journal of the Transportation Research Board, 1538(1), 1-9. http://dx.doi.org/10.1177/0361198196153800101.

Epperson, B. (1994). Evaluating suitability of roadways for bicycle use: toward a cycling level of service standard. Transportation Research Record: Journal of the Transportation Research Board, (1438), 9-16.

Gehl, J. (2015). Cidades para pessoas (3a ed.) São Paulo: Perspectiva.

Gutiérrez, A. (2012). ¿Qué es la movilidad? Elementos para (re) construir las definiciones básicas del campo del transporte. Revista Bitácora Urbano Territorial, 21(2), 61-74. http://dx.doi.org/10.15446/bitacora.

Illich, I. (2005). Energia e equidade. In N. Ludd (Ed.), Apocalipse motorizado: a tirania do automóvel em um planeta poluído (2a ed., pp. 33-71). São Paulo: Conrad Editora do Brasil.

Instituto Brasileiro de Geografia e Estatística - IBGE. (2018). João Pessoa panorama. Recuperado em 16 dezembro de 2018, de https://cidades.ibge.gov.br/brasil/pb/joao-pessoa/panorama

Instituto de Políticas de Transporte \& Desenvolvimento - ITDP. (2017). Guia de planejamento cicloinclusivo. Recuperado em 11 de julho de 2018, de http://itdpbrasil.org/guia-cicloinclusivo/

Instituto de Políticas de Transporte \& Desenvolvimento - ITDP. (2018). Índice de caminhabilidade: ferramenta versão 2.0. Recuperado em 12 de julho de 2018, em http://itdpbrasil.org/icam2/

Maruyama, C. M., \& Simões, F. A. (2014). Arborização urbana e transporte cicloviário: o caso de Chapecó, SC. Revista dos Transportes Públicos, 36(137), 95-114.

Monteiro, F. B., \& Campos, V. B. G. (2011). Métodos de avaliação da qualidade dos espaços para cilistas. In Anais do XXV Congresso de Pesquisa e Ensino em Transportes da ANPET (pp. 1242-1253). Belo Horizonte: ANPET.

Passos, L. A. D., Silveira, F. A., Pita, A. L. L. R., Braga, C. F. C., \& Silveira, J. A. R. (2012). Processo de expansão versus sustentabilidade urbana: reflexão sobre as alternativas de deslocamento na cidade de João Pessoa, PB. urbe. Revista Brasileira de Gestão Urbana, 4(1), 47-59. http://dx.doi.org/10.1590/S2175-33692012000100004.

Providelo, J. K., \& Sanches, S. D. P. (2011). Roadway and traffic characteristics for bicycling. Transportation, 38(5), 765-777. http://dx.doi.org/10.1007/s11116-011-9353-x.

Silva, F. N. (2013). Mobilidade urbana: os desafios do futuro. Cadernos Metrópole, 15(30), 377-388.

http://dx.doi.org/10.1590/2236-9996.2013-3001. 
Silveira, M. O., \& Maia, M. L. A. (2015). Variáveis que influenciam no uso da bicicleta e as crenças da teoria do comportamento planejado. Transportes, 23(1), 24-36. http://dx.doi.org/10.14295/transportes.v23i1.848.

Tischer, V. (2017). Validação de sistema de parâmetros técnicos de mobilidade urbana aplicados para sistema cicloviário. urbe. Revista Brasileira de Gestão Urbana, 9(3), 587-604. http://dx.doi.org/10.1590/21753369.009.003.ao15.

Transportation Research Board - TRB. (2000). Highway capacity manual. Washington: Transportation Research Board, National Research Council.

Transporte Ativo. LABMOB. (2018). Parceria nacional pela mobilidade por bicicleta: pesquisa perfil do ciclista 2018. Rio de Janeiro. Recuperado em 27 agosto de 2018, de http://transporteativo.org.br/ta/?page_id=11570

Vasconcellos, E. A. D. (2014). Políticas de transporte no Brasil: a construção da mobilidade excludente (1a ed.). Barueri: Manole.

Villada, C. A. G., \& Portugal, L. D. S. (2015). Mobilidade sustentável e o desenvolvimento orientado ao transporte sustentável. In Anais do XXIX Congresso Nacional de Pesquisa em Transporte da ANPET (pp. 2743-2754). Ouro Preto: ANPET.

\section{Editor: Fábio Duarte}

Recebido: Abr. 12, 2019

Aprovado: Dez. 15, 2019 